\title{
The experience of implementation with Agile Business Process Management
}

\author{
Denis Rodríguez*, Enrique Silva Molina \\ Electrical-Electronic-Computer Faculty, National Engineer University, Nicaragua
}

\author{
A R T I C L E I N F O \\ Article history: \\ Received: 29 June, 2018 \\ Accepted: 02 August, 2018 \\ Online: 12 August, 2018
}

Keywords:

Agile Business Process

Management

Business Process Management

Wiki

\begin{abstract}
A B S T R A C T
This paper is an extension of work originally presented at the Convention of Central America and Panama XXX VII- The Institute of Electrical and Electronic Engineers -2017. We have extended our previous work by presenting the initial results of how social technologies in particular wikis has the potential for Information Technology support of a cooperative community knowledge generation.

This paper outlines an experience in the implementation of a multidisciplinary research project - AGILe busIness PrOcess (AGILIPO), applied to an important organization in Nicaragua. In addition, it focused on improving key process by describing through collaborative tools which foster end user collaboration and organization knowledge.

We gathered evidence that blogs and podcasts couldn't afford to allow users on collaborative tasks of AGILIPO. The principal contributions of this work are the lessons learned from the experience of applying AGILIPO to an organization in Nicaragua, the key elements in achieving success in the application, the conditions that were brought together in order to use AGILIPO, the drawbacks during the experience and the relevant limitations of AGILIPO and how we can improve process by agile Business Process Management.
\end{abstract}

\section{Introduction}

Business Process Management (BPM) is a discipline which has been around since the early 90 s, launched by the article by Hammer (1990) and reinforced by the book by Hammer and Champy (1993) on Business Process Reengineering (BPR). Hammer (1990) stressed that Information Technology (IT) made it possible for companies to undertake major revisions in the way they did work [1].

One of the methodologies of BPM agile found in the bibliographic searches carried out in this work was AGILIPO. In this literature review they were not experiences prior documented of the implementation of the AGILIPO methodology in an organization. Thus, what is innovative of this work is to implement AGILIPO in an organization in Nicaragua [2].

Agile BPM represents the next generation of business process management designed to flexibly address all types of processes to support all forms of work. It combines traditional Business Process IT-Management (BPM) style predefined processes, along with Adaptive Case Management (ACM) style dynamic work support.

"Corresponding Author: Denis Rodríguez, FEC-UNI, Managua, Nicaragua, +1202-974-3009, rodrigde@paho.org
Agile BPM is designed to flexibly address all types of processes used to conduct business: structured, unstructured, and hybrid process types to support all forms of work [3].

The methodology used in researching this paper has a qualitative approach with a practical action-oriented research design, which the investigator carried out a literature review of the area of the knowledge of BPM and Agile BPM. It deepened through an analysis of the background of BPM and Agile BPM. The result of this analysis was the selection of a multidisciplinary research project AGILe busIness PrOcess (AGILIPO). Next, the investigator developed the experience to apply AGILIPO to an organization in Nicaragua. Based on this experience of applying AGILIPO, we learned a group of lessons [4].

This research project shows the lessons learned from the experience of applying AGILIPO to an organization in Nicaragua, the key elements to achieve success in the application, the conditions that we should have in order to use AGILIPO, the drawbacks during the experience and the relevant limitations of AGILIPO [4].

The principal contributions of this work are the lessons learned from the experience of applying AGILIPO to an organization in 


\section{Rodríguez et al. / Advances in Science, Technology and Engineering Systems Journal Vol. 3, No. 4, 284-294 (2018)}

Nicaragua. On the basis of this experience some limitations of AGILIPO were found [2].

From the experience of applying AGILIPO evidence it was learned that this increases the participation of the users in the phase of modeling and implementation of key processes. On the other hand, the search in the databases for research during this work showed the lack of research on the methodology agile BPM.

\section{Analysis of BPM background}

\subsection{Definitions}

What is a process?

A process corresponds to the representation of a set of actions (activities) that are done (carried out), under certain conditions (rules) and that can trigger or cause events [5].

What is a business process?

A business process is a set of activities, which promoted by events and carried out in a certain sequence create value for a client (internal or external) [5].

What is a key process?

A business process which, from management's point of view, is critical to customer service and satisfaction, has a competitive advantage, or has the success of the firm's strategy [2].

What is Business Process Management (BPM)?

Business Process Management (BPM) is a management discipline that integrates the strategy and goals of an organization with the expectation and needs of customer by focusing on end-toend process. BPM comprises strategies, goals, culture, organizational structures, roles, policies, methodologies, and IT tools to (a) analyze, design, implement, control, and continuously improve end-to-end processes, and (b) to establish process governance [6].

After WWII, applying science to process became front and center as W. Edwards Deming and Joseph Juran taught the Japanese about the power of quality management. Their work and the work of others triggered a wave of Total Quality Management (TQM), spurred on by the publications of Deming and Juran in 1982 as shown below. The emphasis was not so much on the design of new processes, but on statistical measurements as a means of improving existing work practices and quality [7].

Then a decade later, the 1992 blockbuster books, Process Innovation and Reengineering the Corporation, hit corporate board rooms, and reengineering work through information technology took off. In this second wave of business process management, processes were manually reengineered, and through a one-time, big-bang activity, cast in concrete in the bowels of today's automated Enterprise Resource Planning (ERP) and other packaged systems. Although "downsizing" is the moniker most remembered from Business Process Reengineering (BPR), it was technological enablement-including office automation-that allowed companies to tear down internal silos and reengineer endto-end business processes that spanned individual functional departments (silos) [7].
In the third wave of process management, the business process was freed from its concrete castings and made the central focus and basic building block of automation and business systems. Processes became first-class citizens in the world of automation. Change was the primary design goal because in the world of business process management: the ability to change is far more prized than the ability to create in the first place. It is through agile business process management that end-to-end processes can be monitored, continuously improved and optimized. Feedback of results, agility and adaptability are the bywords of the third wave [7].

Industry 4.0 denotes the Fourth Industrial Revolution, a term introduced in 2011 at the Hannover Messe, one of the world's largest trade shows, and since then widely used by German industry and government [8-5].

\section{BPM as Support for Industry 4.0 and E-Commerce}

The new industrial revolution will have a strong impact on the relation of BPM and e-Commerce because it moves manufacturing and production from a centralized to a decentralized paradigm. This will require a widespread adoption of smart interconnection of machinery and systems, not only at the same production site but also across the entire organizational ecosystem. An enormous potential opens up for innovation in business processes and in the way society interacts at a global level [9].

\section{Agile BPM}

One of the reasons why BPM is losing momentum is the lack of strategic alignment of its programs. On the one hand, organizations involved in BPM initiatives still mainly focus their efforts on the early stages of the BPM lifecycle, i.e. on process identification and discovery [10].

For many years, we have been arguing that traditional models of management, sponsorship, and project management have not coped with the increasing rate of change. In two separate Harvard Business Review articles, Donald Sull argues for a values-based agile model of business and Gary Hamel presents 25 grand challenges designed to redesign all aspects of management theory and practice to address the fact that "modern models of management" have reached their limits [11].

Business process management (BPM) encompasses the discovery, modelling, monitoring, analysis, and improvement of business processes. Traditional BPM limitations in addressing changes in business requirements have resulted in a number of agile BPM approaches that seek to accelerate the redesign of business process models [12].

Another alternative to highly engineered processes might he called "agile" methods. They are less focused on the specific steps to be followed in a process, and more oriented to the managerial and cultural context surrounding the process. Instead of detailed process flows, for example: agile methods might emphasize the size and composition of process teams, a highly iterative workflow, and a culture of urgency. This is the case, for example, in the agile method known as "extreme programming." [13].

Next-generation Agile BPM is designed to address all of the requirements of managing work in today's enterprise: from streamlining routine, repeated business processes to managing 
dynamically evolving business cases involving teamwork, collaboration, and judgment across and among diverse sets of process participants [3].

Achieving successful BPM solutions starts with an agile approach. An agile approach supporting stronger business and IT collaboration on BPM and minimizes the challenges of ineffective requirement definition. By engaging business in the actual development process, design problems can be surfaced more quickly and this helps to reduce the typically long development cycles often seen in BPM. Finally, and perhaps most importantly, an agile BPM approach can institutionalize a partnership between business and IT by providing a foundation for shared commitment, role management and process ownership [14].

\section{AGILe busIness PrOcess (AGILIPO)}

AGILIPO - AGILe busIness PrOcess - is a multidisciplinary research project that has been put forward within the scope of a wide-raging research programme aimed at integrating the development of computer-based artifacts for organizations with the accumulated knowledge on organizational design [15].

AGILIPO approach is based on the following steps:

1. Defining the process according to its goals.

2. Defining the process according to its agency and context, using a classificatory framework based on organizational routines.

3. Describing the process using a wiki-like approach, where collaboration, user empowerment and tacit knowledge usage are key principles.

4. Fine-tuning the description through an ontological approach known as folksonomy.

5. Validation of the process.

AGILIPO approach steps are shown in Figure 1.

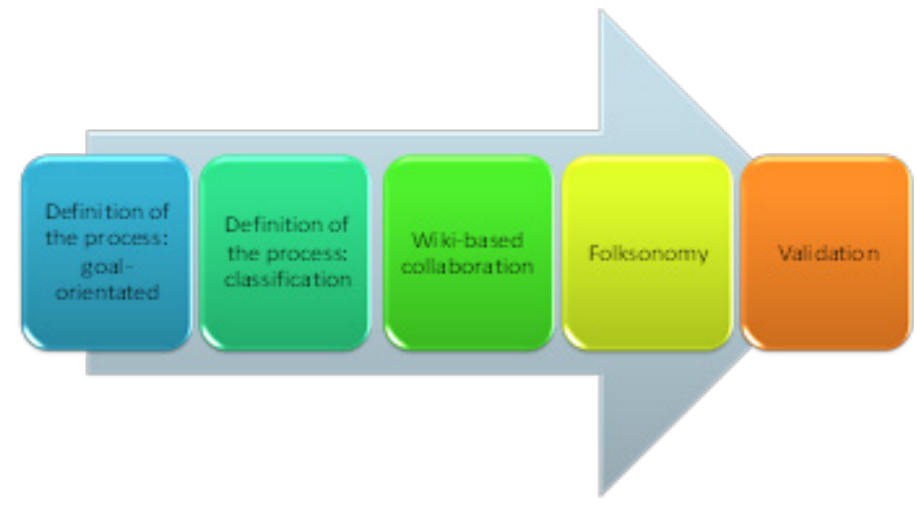

Figure 1: Proposal AGILIPO approach

\section{Definition of the process: goal-oriented}

Goal-orientation mirrors the approach we take to goals in our own lives and lends itself to business user involvement in the creation and management of processes. This also extends to routine tracking of plan execution to detect problems as they occur, or even better before they do, in order to take timely and appropriate actions [15].

\section{Definition of the process: classification}

On the topic of standardization (and eventual reuse) if we know the process type(s) and the process instance(s) that we are dealing with, this will save much time and effort at the outset. Classification of processes is a method which has been talked about in the literature. There have been many initiatives aimed at cataloguing generic business processes, each proposing classifications of their own, including the MIT process handbook (Malone, 1999) or the Process Classification Framework by the American Productivity and Quality Center's International Benchmarking Clearinghouse (APQC, 2006) [15].

\section{Wiki-based collaboration}

In the context of an agile BPM methodology, we proposed that a wiki-type tool can be created for the collective description of business processes. In this context, three aspects may be considered when evaluating wiki-type scenarios [15]:

1. The degree of organization of the BPM team.

2. The degree of specificity of wiki objects (goals, sub-goals, activities, roles, etc.).

3. The degree of desired process completeness.

Wikis, blogs/photoblogs and podcasts (and its video incarnation, the vodcast) carry the potential of complementing, improving and adding new collaborative dimensions to the many Web-based medical/health education, Continuing Professional Development (CPD), and research services currently in existence. They offer many unique and powerful information sharing and collaboration features. They also afford users the added advantage of reducing the technical skill required to use these features, by allowing users to focus on the information and collaborative tasks themselves with few delivery obstacles [16].

\section{Folksonomy}

Folksonomies are an emergent phenomenon of the social Web. They arise from data about how people associate terms with content that they generate, share, or consume (Gruber, 2006). It is claimed that Folksonomies have many advantages over controlled vocabularies or formal taxonomies. Tagging has dramatically lower costs because there are no complicated, hierarchically organized nomenclatures to learn. Users simply create and apply tags on the fly. Folksonomies are inherently open-ended and therefore respond quickly to changes and innovations in the way users categorize content (Wu et al., 2006) [15].

\section{Validation}

The modeling of business processes is never finished because the process itself is never complete. In order to overcome such a realization, a validation step must be adopted (Kuhne, 2008). Validation should give immediate and continuous feedback to business process designers about weaknesses and inconsistencies in possibly incomplete models. The established modeling process with sequential modeling, validation and evolution stages should be replaced by a modeling process with integrated validation support [15].

This research is not an attempt to generalize probabilistically the results to broader populations, nor necessarily obtain representative samples. This approach used interpretive practices that make the organization visible where research was developed and proposals made to transform the way in which people interact with the key processes. This became a representation in the form 
of observations for the AGILIPO proposed methodology, academic articles, and diagrams of modeled key processes [2].

\section{The experience of implementing AGILIPO in an organization in Nicaragua}

Current approaches to BPM still work on the AS-IS/TO-BE paradigm, inherited from the Business Process Reengineering (BPR) era from the nineties. BPR is a top-down, holistic, and cross- cutting approach that takes months of analysis and impact assessment to achieve. [17-18]. The problems with the AS- IS/TO$\mathrm{BE}$ approaches are related to the temporal gap between the modeling and implementation phases as well as the lack of involvement of the users [15]. These problems have been little addressed by BPM and agile BPM. That is why they are important at present.

After searching the databases of Scopues-Elsevier, ScienceDirect, Google Scholar and IEEE, articles on neither the implementation of AGILIPO nor experiences of AGILIPO in Nicaragua were found. Thus, what is innovative in this work is to implement AGILIPO in an organization in Nicaragua with live business processes.

Although Business Process Management implementation is usually associated with large scale business, implementing it on small medium enterprise may also be a good consideration for Small Medium Enterprises (SMEs) owners. SMEs are nonsubsidiary, independent firms which employ fewer than a given number of employees [19]. Upon regarding this organization in Nicaragua as a SMEs, the implementation of AGILIPO should be taken into account.

The experience was carried out in the natural and daily environment of the PAHO/WHO Representative Office in Nicaragua in 2015 and included the key processes for the biennium 2014-2015 [2].

The key processes were:

1. Local and international purchases (procurements of goods).

2. Service contracts (contracts of providers).

3. Temporary advisor contracts (contract of temporary people).

Furthermore, this experience responds to the AGILIPO team requirement to improve even more the key processes of PAHO/WHO Nicaragua of the biennium 2016-2017. Besides, it tries to respond what types of other social network tools as blog and podcast could be feasible for AGILIPO.

The experience was divided into three stages:

The first one included semi-structured interview of project's managers and administrative-technical committee (operational structure linked with the review of processes in the Representative Office) [2].

The second stage included development of the experience using the proposal methodology AGILIPO with the key processes. For this activity there was created the AGILIPO team, which was integrated by a representative of each level of the organization chart of the Representative Office and the investigators [2].
The third one included an evaluation of the use of other social network tools (blogs and podcasts) for step 3 to 5 of AGILIPO and improves the key process of PAHO/WHO Nicaragua of the biennium 2016-2017 by using the best practices of modeling with Bizagi.

\subsection{Results obtained in the first stage of the experience}

The purpose of the first interview of the four project managers was to compile information on the knowledge of the interviewees of the methodology of process management that the organization has used in the last 6 years. In the interview all the interviewees agreed that the organization had tried to be efficient and that the companies should be flexible and adapt to change [2].

The preliminary results of the first interview warn the AGILIPO team that the project managers had little knowledge about BPM and agile BPM. Thus the investigators trained the interviewees on the basic concepts of BPM and agile BPM. In the opinion of the investigators a condition for using AGILIPO should be training of the interviewees and the AGILIPO team on the basic concepts of BPM and agile BPM to improve the knowledge of the interviewees about BPM and agile BPM.

The second interview of the project managers and the administrative technical committee, through questionnaire No. 2, had the purpose of compiling information on the knowledge of the interviewees on the possibility of the use of methodology agile BPM for management of the processes of the Representative Office. $89 \%$ of the participants thought that the agile BPM could be used in the operational processes. $100 \%$ believed that increasing the participation of the users could help to improve the management. $89 \%$ believed that it was feasible to use collaborative tools that exist in the organization [2].

The AGILIPO team agreed with the interviewees who were open to changes and improvements in the processes of the organization and in strengthening the use of tools already existing in the organization. The opinion of the interviewees were taken into account to help improving the process and to empower the users to share their ideas and proposals to work on the issues.

\subsection{Results obtained in the second stage of the experience}

In the second stage of the experience had participated five peoples of the administrative technical committee $(75 \%$ of the committee) through a Wiki site [2].

The first round of the experience was carried out with the three operational processes of the general services unit. The definition of the process aimed at step 1 was complicated since the participants could not link the modeled processes with the goals of the Representative Office. The definition of the processes according to this agency (organization) and context was complicated because the participants did not understand the classification approach defined by AGILIPO and they did not reach a consensus. That issue did not allow participants to describe the process with the Wiki in conjunction of the folksonomy approach [2].

Based on the results of the first round; the Representative took a decision on how to model the key process of the WHO/PAHO Nicaragua. Below are the results of the execution of the key 
processes of procurements of goods shown using the five steps of AGILIPO [2].

Step 1: Definition of the process: goal-oriented

In this step $75 \%$ of the interviewees did not link the process of procurement of goods to any product of its corresponding project in the Plan of the bi-annual Budget 2014-2015. Furthermore 100\% of the interviewees did not define the objectives of the process. $75 \%$ of the interviewees did not reach a consensus on who should do the tasks (human or technological actors).

The definition of the process was guided by AGILIPO approach; it helped to detect the inconsistency that existed in the products of the projects of the biennium 2014-2015, which were not linked clearly to the key processes of the organization [2].

Step 2: Definition of the process: classification

Defining the process according to its agency and context, using a classificatory framework based on organizational routines [15].

Due to the difficulties that the members of the technical committee-administrator had in using the classification of step 2 of AGILIPO, the investigators decided to obtain evidence of this difficulty applying the third interview through questionnaire No. 3 . The purpose of this questionnaire was to compile information on how they used the classification based on Howard-Grenville (2006) [4].

The questions of the questionnaire No. 3 were coded in the Figure 2 with this syntax: Questionnaire number $\mathrm{X}$ and Question number Y. Example: Q3Q1.

The questions of the questionnaire No. 3 for the process of procurements of goods are listed below:

1. Do you believe that the process of procurements is necessary? [Q3Q1]

2. Do you believe that the process of procurements has a clear definition? [Q3Q2]

3. You believe that the process of procurements has a clear definition of who should do it? [Q3Q3]

4. Do you believe that the process of procurements has a weak embeddedness? [Q3Q4]

5. Do you believe that the process of procurements is flexible? [Q3Q5]

6. Do you believe that the process of procurements has some change probabilities? [Q3Q6]

Regarding the classification based on Howard-Grenville (2006), all the participants agreed on what had to be made. Although $75 \%$ believed that the process was not flexible, and they did not reach a consensus on who should make this process. Using this classification was complicated for the interviewees, due to a lack of understanding that the columns were related. For example, the embeddedness of the process, with the actors primary orientation, the performances of the flexible process, the changes in process over time, process labels and characteristics over time[2]. The overall of the answers of the questionnaire No.3 is shown in Figure 2.

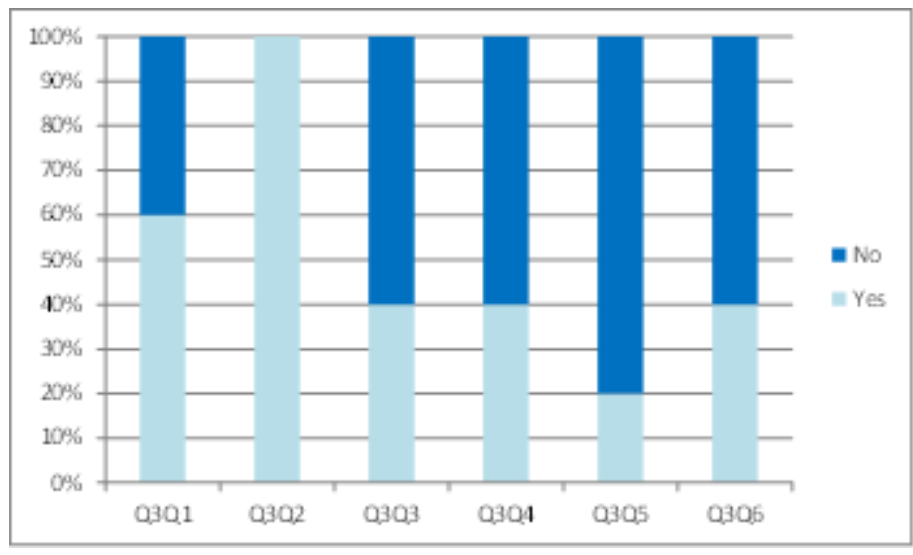

Figure 2: Abstract of responses to the questions of the questionnaire No.3

The classification of processes constituted a limitation of AGILIPO. Since all the participants did not understand how to use it. The author suggests changing to the MIT process classification or the framework of classification of processes of APQC [2].

Step 3: Wiki-based collaboration

Social technologies provide a range of collaboration and communication tools such as blogs, wikis, forums, chat platforms, etc. that support user interaction through social computing features. These features enable users to easily capture and share the knowledge and expertise that is needed to do their work. This sharing of information encourages collaboration, improves innovation, and targets relevant content to the people who have to see it [20].

Traditional process elicitation methods are expensive and time consuming. Recently, a trend toward collaborative, user-centric, on-line business process modeling can be observed [21].

Enterprise social networks are gaining momentum as a platform for collaboration between members of an enterprise, leading to the notion of Enterprise 2.0 [22].

Upon considering the issues suggested by the authors for the use of the Wiki:

- The level of organization of the team AGILIPO, in this case is made up of the investigator and the members of the technical committee-administrator. The mapping and description of the process, including the number of participants of different organizational units, were based on the rules established by the Representative Office in order to guarantee their consistency. The Wiki have a mechanics of horizontal work that provided the proposals of the participants in the description of the process.

- The degree of specificity of the objects of the Wiki (goals, activities, roles). The structure of the data, related to the definition of the process was based on the knowledge of the participants in the experience maintaining the greatest possible simplicity.

- From the standpoint of social intelligence, we can observe that the more collective intelligence is needed for a given task, a lesser degree of organization is required. . In other words to greater participation in the development of an artifact, the greater the probability of its completion is increased. During 
the execution of the experience, a description by consensus was obtained for the most part.

Wiki was used to model the key processes, through the cooperative knowledge of the AGILIPO team. With the Wiki an active participation of the AGILIPO team in the modeling of the key process was seen. This participation made it possible to carry out contributions to the modeled key process [2].

\section{Step 4: Folksonomy}

The folksonomy was the most interesting step in the experience. Since the participants were accustomed to working with methodologies of structured management as the logical Framework and the Results-based Management. These methodologies are from the top down. In the opinion of the participants, this made it difficult for them to be able to prepare the labels without a hierarchy resulting in the participants having equal decision-making power [2].

The transcription of the Wiki in the creation of labels of the process of procurement of goods, through the folksonomy, was developed in four interactions. The last round is shown below [2]:

- Create request of purchase

- Confirm if it is planned

- Authorize request

- Notify It staff member the change

- Generate offers

- Approve offer

- Notify there is not offer

- Review budget

- Notify change in budget

- Create purchase order

- Authorize purchase order

- Cancel purchase order

- Send purchase order to supplier

- Receive products

- Review products

- Notify claim of goods

- Pay invoice to supplier

- Close purchase order

The labels created by the members of the AGILIPO team are tabulated in Table 1. These labels described the process of procurement of goods (Process 1). These labels were grouped by synonyms synthesizing them in verbs or actions that describe the analyzed process. Finally, the labels are ordered by coincidences in order which they were written by the members of the AGILIPO team and the results of the tasks of the process analyzed [2].
Table 1: Review of labels of the folksonomy - Process 1

\begin{tabular}{|c|c|c|c|c|c|}
\hline Labels & Person 1 & Person 2 & Person 3 & Person 4 & Person 5 \\
\hline Create & 1 & & & & \\
\hline Request & & 1 & 1 & & \\
\hline $\begin{array}{l}\text { Request } \\
\text { purchase }\end{array}$ & & & & 1 & \\
\hline $\begin{array}{l}\text { Authorize } \\
\text { request }\end{array}$ & & 1 & & & 1 \\
\hline Quotations & & 1 & & & 1 \\
\hline $\begin{array}{l}\text { Authorize } \\
\text { quotation }\end{array}$ & 1 & & & & \\
\hline $\begin{array}{l}\text { Create } \\
\text { purchase }\end{array}$ & & & 1 & & 1 \\
\hline Notify vendor & & 1 & & 1 & \\
\hline Reject request & & & 1 & 1 & \\
\hline Receive goods & 1 & & & & 1 \\
\hline Check goods & & & 1 & 1 & \\
\hline Goods claim & & 1 & & 1 & \\
\hline $\begin{array}{l}\text { Business rules } \\
\text { ok }\end{array}$ & 1 & & & & \\
\hline Pay to vendor & & & & 1 & 1 \\
\hline No money & 1 & & & 1 & 1 \\
\hline
\end{tabular}

Finally, the labels are ordered by coincidences and in order in which they were written by the members of the AGILIPO team and the results of the tasks of the process analyzed [2].

- Register

- Request

- Request purchase

- Authorize request

- Offers

- Approve offer

- Create purchase

- Notify supplier

- Reject request

- Receive goods

- Review goods

- Demand of purchase

- $\quad$ Business rules OK

- Pay supplier

- Defund

The folksonomy used jointly with the Wiki was the reason the participants described the key processes and created the labels that helped to improve the key processes [2].

Step 5: Validation

Taking into consideration that PAHO/WHO Nicaragua cannot implement changes in their key processes as part of this work. The 
investigators took a decision of carry out a simulation in order to validate the modeled processes [2].

The procurement units had six kinds of purchases services. As part of the validation, the investigators reviewed those six cross functional flowchart and create one. Based on that cross functional flowchart, the investigators create the old BPM diagram of procurements process. The old BPM diagram of procurements is shown in Figure 3.

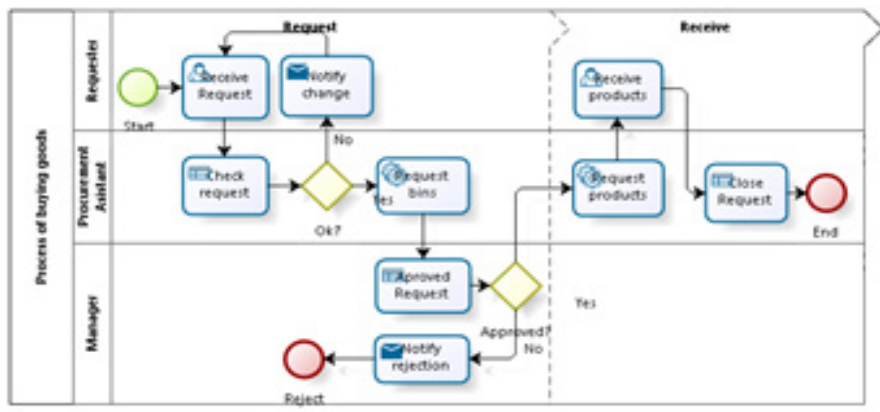

Figure 3: Old BPM diagram of procurements process

The procurement units had two kinds of services contracts. As part of the validation, the investigators reviewed those tow cross functional flowchart and create one. Based on that cross functional flowchart, the investigators create the old BPM diagram of services contracts. The old BPM diagram of services contracts is shown in Figure 4.

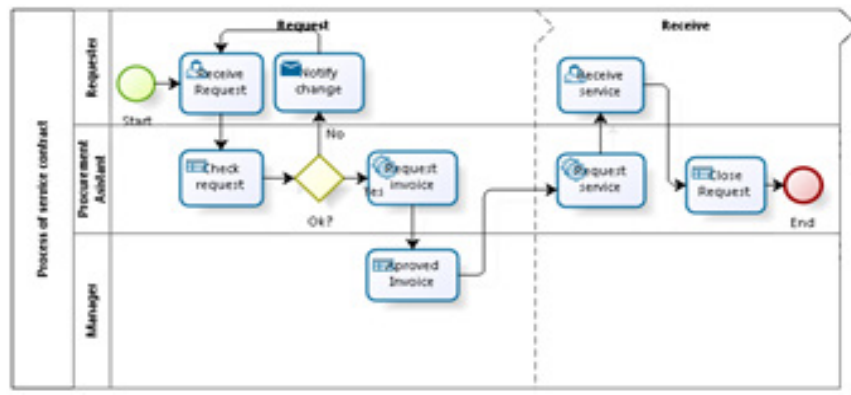

Figure 4: Old BPM diagram of services process

The Human Resources (HR) units had three kinds of services contracts. As part of the validation, the investigators reviewed those three cross functional flowchart and create one. Based on that cross functional flowchart, the investigators create the old BPM diagram of recruitment temporary staff. The old BPM diagram of temporary staff is shown in Figure 5.

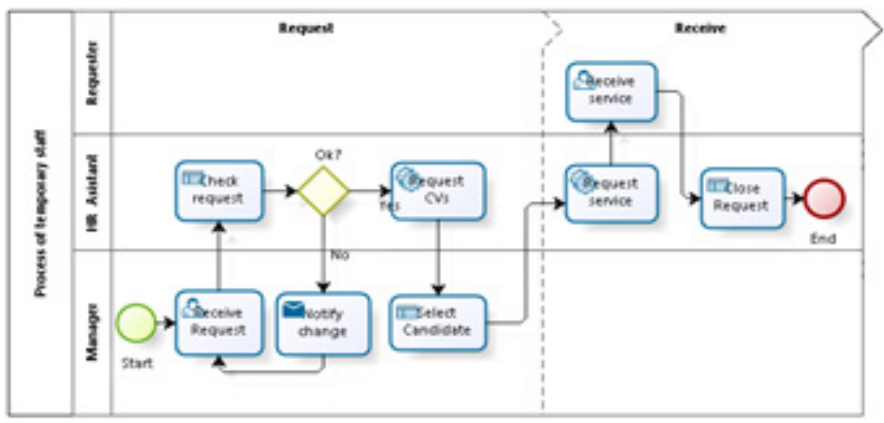

Figure 5: Old BPM diagram of temporary staff
Based on the log of the Wiki in conjunction with the labels produce through the folksonomy process we create a new BPM diagram of the process of procurement of goods, services contracts, and recruitment of temporary staff.

The resulting new BPM diagram of procurements process based on the best practices in modeling of Bizagi is shown in Figure 6. The improvements of the old BPM diagram were the following:

- Use the standard BPMN ( Do not use unit names).

- Simplification of the diagrams (Combine two roles which bellow to the same organizational unit ).

- Maintain the logical sequence and cleaning (Eliminate duplicated end events).

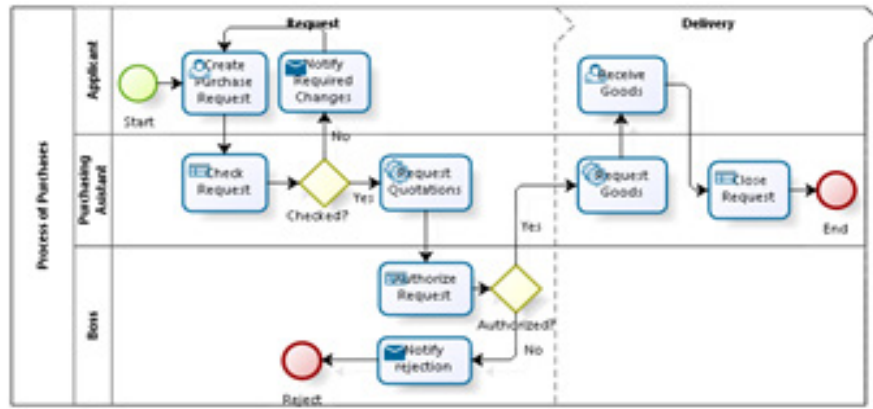

Figure 6: New BPM diagram of procurements process

The resulting new BPM diagram of service contracts process based on the best practices in modeling of Bizagi is shown in Figure 7. The improvements of the old BPM diagram were the following:

- Use the standard BPMN ( Use standard job title).

- Maintain the logical sequence and cleaning (Add rejection task after authorize tasks)

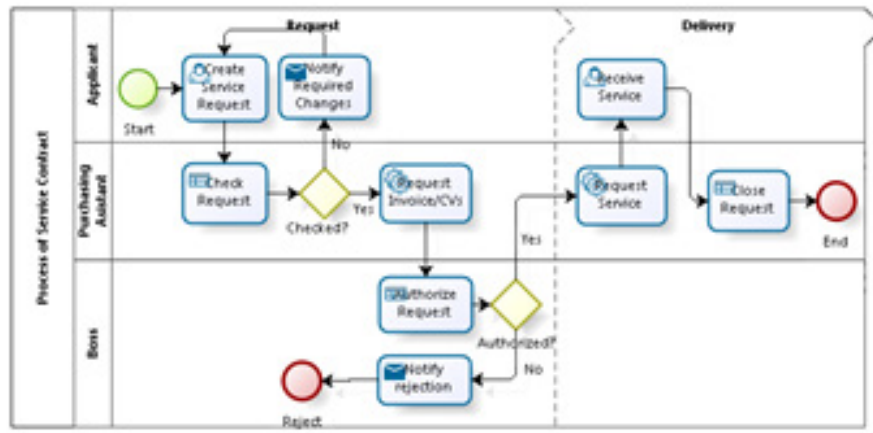

Figure 7: New BPM diagram of service contracts process

The resulting new BPM diagram of recruitment temporary staff process based on the best practices in modeling of Bizagi is shown in Figure 8. The improvements of the old BPM diagram were the following:

- Simplification of the diagrams (Combine two roles which bellow to the same organizational unit ).

- Maintain the logical sequence and cleaning (Transfer two tasks from the boss to the applicant, Add a rejection task after a decision task). 


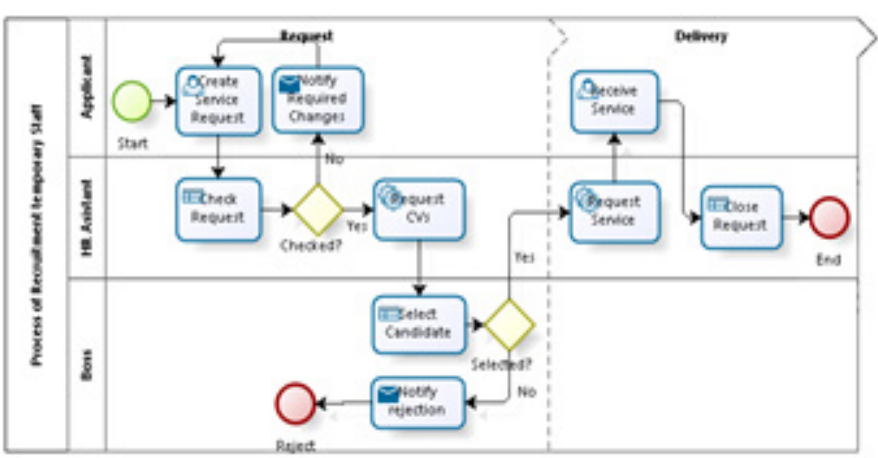

Figure 8: New BPM diagram of recruitment temporary staff process

Considering the limitations of time on the work of the thesis and the regulations of $\mathrm{PAHO} / \mathrm{WHO}$ to authorize changes in their processes, a validation was carried out through a simulation on the basis of a scenario: 30 calendar days of execution, along with the personnel that worked in the Representative Office during the development of this research [2].

Bizagi Simulation comprises of four levels. Each subsequent level incorporates additional information exhibiting more complexity than the preceding one, thereby providing a detailed analysis of your processes [23].

\section{Process Validation \\ 2. Time Analysis \\ 3. Resource Analysis \\ 4. Calendar Analysis}

To illustrate each of the simulation levels let us consider the level 1 for the Procurement Process.

\section{Level 1: Process Validation}

This level of the simulation validates gateways, messages, decisions and routing and all the sequence flow are fine. The results of the Bizagi simulation level one for Procurement Process are tabulated in Table 2.

Table 2.Results of process validation of Procurement Process

\begin{tabular}{|l|l|r|}
\hline Name & Type & Tokens completed \\
\hline Process of Purchases & Process & 1000 \\
\hline Start & Start event & 1000 \\
\hline Checked? & Gateway & 2022 \\
\hline Authorized? & Gateway & 1000 \\
\hline Reject & End event & 504 \\
\hline End & End event & 496 \\
\hline $\begin{array}{l}\text { Create Purchase } \\
\text { Request }\end{array}$ & Task & 2022 \\
\hline Check Request & Task & 2022 \\
\hline Request Quotations & Task & 1000 \\
\hline $\begin{array}{l}\text { Notify Required } \\
\text { Changes }\end{array}$ & Task & 1022 \\
\hline Authorize Request & Task & 1000 \\
\hline Notify rejection & Task & 504 \\
\hline Request Goods & Task & 496 \\
\hline Receive Goods & Task & 496 \\
\hline Close Request & Task & 496 \\
\hline Process of Purchases & Process & 1000 \\
\hline
\end{tabular}

\subsection{Results obtained in the third stage of the experience}

In the third stage of the experience participated five peoples of the administrative technical committee ( $75 \%$ of the committee) through a Google's blogger, WordPress site with podcast, a SharePoint blogs site with podcasts, and a SharePoint blogs site.

The AGILIPO team tested the Google's blogger site. Only 20\% of the AGILIPO team created his/her account. Besides, the team tested Apple's Podcasts. The team was unable to subscribe to a podcast channel on iTunes. The team agreed that they preferred a technology available in his working environment. Microsoft SharePoint is a technology that includes blogs and RSS feeder and is available on PAHO/WHO.

As part of evaluate the use of podcast and blog for step 3 to 5 of AGILIPO. The AGILIPO team used the outcome of the step 1 and 2 in stage two of this experience.

\section{Step 3: Podcast-based collaboration}

The investigators created a SharePoint blogs site with RSS feeds and configure the Outlook RSS reader watching the SharePoint site. After that, they made a quick guide to help AGILIPO team to create a short podcast and upload the audio files on the SharePoint site. Only $20 \%$ of the team could create three small audio files of one or two minutes. To deal with this issue the investigators trained to AGILIPO team how to create an audio file. After that, only $40 \%$ of the team could create three additional small audio files of two minutes. All the AGILIPO team agreed that describing the process using podcast approach was not easy to follow the discussion and describe the process. They spent much time listening all audio files.

\section{Step 4: Folksonomy through Podcast}

The AGILIPO team used the SharePoint blogs site to tune the description through folksonomy. Only $40 \%$ of the AGILIPO team could create eight audio files for same number of labels. The AGILIPO team agreed that tune the description by folksonomy through Podcast was very confused. They said that was so complicated listened audio files and understand the labels.

Step 3: Blogs-based collaboration

The investigators created a SharePoint blogs and a quick reference guide to help AGILIPO team to post information on the SharePoint site. The investigators started the blogs and all AGILIPO team members posted information to describing the key process of PAHO/WHO Nicaragua. All AGILIPO team agreed that they felt a little concern about who posted which information, rejected or support some information. They preferred the Wiki approach, because they do not see audit tracks and felt more comfortable given feedbacks.

\section{Step 4: Folksonomy through Blogs}

In the case of fine-tuning the description of the process through folksonomy the AGILIPO team agreed that was more complicated to follow the comments, feed backs and get a consensus. They spend more time reading the blogs to label the key process of PAHO/WHO Nicaragua. The AGILIPO team agreed that the Wiki approach was easier to describing the process and tune the description through folksonomy. 
The transcription of the SharePoint blogs in the creation of labels of the process of service contracts through the folksonomy, was developed in four interactions. The last round is shown below

- Create request of contract

- Authorize request

- Notify changes

- Review budget

- Notify change in budget

- Authorize contract of service

- Cancel contract of service

- Send to review in department of legal advisory services

- Sign contract

- Request payment

- Pay invoice to provider

- Provider offers services

- Request report of services

- Pay the bill

- Close contract of service

The labels created by the members of the AGILIPO team are tabulated in Table 2. These labels described the process of services (Process 2). This process combines the process of services and recruitment of temporary staff and this is an improvement of both services. These labels were grouped by synonyms synthesizing them in verbs or actions that describe the analyzed process. Finally, the labels are ordered by coincidences in order which they were written by the members of the AGILIPO team and the results of the tasks of the process analyzed.

Table 3: Review of labels of the folksonomy - Service 2

\begin{tabular}{|c|c|c|c|c|c|}
\hline Labels & Person 1 & Person 2 & Person 3 & Person 4 & Person 5 \\
\hline Create & 1 & & & 1 & 1 \\
\hline Check & & 1 & 1 & & \\
\hline $\begin{array}{l}\text { Request } \\
\text { invoice }\end{array}$ & & 1 & & 1 & \\
\hline $\begin{array}{l}\text { Authorize } \\
\text { request }\end{array}$ & 1 & & & & \\
\hline $\begin{array}{l}\text { Request } \\
\text { service }\end{array}$ & & & & 1 & 1 \\
\hline $\begin{array}{l}\text { Authorize } \\
\text { Invoice }\end{array}$ & 1 & 1 & & & \\
\hline Notify vendor & & & & & 1 \\
\hline Notify changes & & 1 & & 1 & 1 \\
\hline $\begin{array}{l}\text { Receive } \\
\text { services }\end{array}$ & 1 & & & 1 & \\
\hline Pay the bill & 1 & & & & \\
\hline Close request & & 1 & 1 & 1 & \\
\hline Service claim & & & & 1 & \\
\hline No money & & & 1 & & \\
\hline
\end{tabular}

Finally, the labels are ordered by coincidences and in order in which they were written by the members of the AGILIPO team and the results of the tasks for the improve process of services are:

- Create

- Check

- Request invoice

- Request service

- Authorize invoice

- Notify changes

- Receive services

- Close request

\section{Improve the key process of PAHO/WHO Nicaragua 2016-2017}

After analyzing the description of the improved process of service contracts using blogs approach and applying the best practices of Bizagi, the investigators create a new BPM diagram of the improved process of service contract. The AGILIPO team agreed that some steps of both process could be combined and improve the logic sequence of the process. The result diagram was easy to understand for the team.

The resulting new BPM diagram of procurements process based on the best practices in modeling of Bizagi is shown in Figure 9. The improvements of the old BPM diagram were the following:

- Simplification of the diagrams (Combine two roles which bellow to the same organizational unit ).

- Maintain the logical sequence and cleaning (Eliminate duplicated tasks).

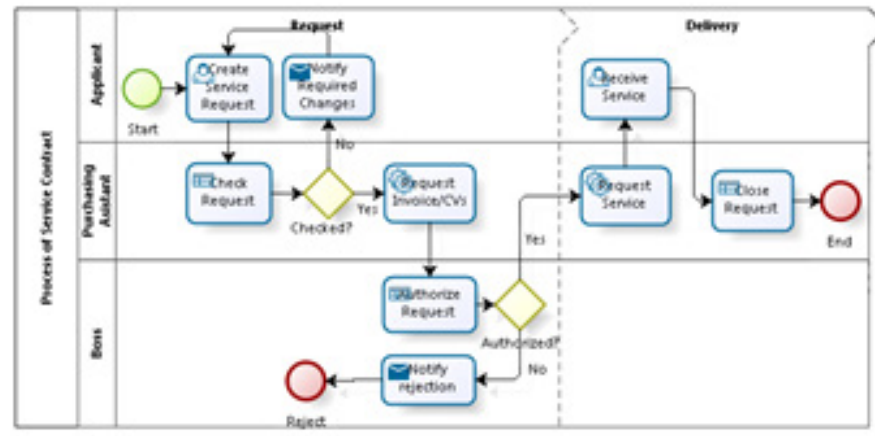

Figure 9: New BPM diagram of the improved process of service

\section{Learning Lessons of the experience}

The principal contribution of this research project carried out and synthesized in this article is described as a group of lessons learned about the basis of the experience to apply AGILIPO to an organization in Nicaragua. The lessons learned are detailed below [2]:

- Based on the experience of applying AGILIPO, we learned that a key element to achieve success is to write questions in order to determine the key processes. 
- It was learned that a condition to use AGILIPO should be the training about BPM concepts for the members of the AGILIPO team..

- It was found that another condition to use AGILIPO should be the definition of the level of training, roles, and level of the organization chart of the participants who will be part of the AGILIPO team.

- It was noticed that the AGILIPO team had several drawbacks in classifying the processes; it was very difficult for the participants to use of AGILIPO classification.

In the second stage of the experience we modeled no key process and the AGILIPO team realized that the outcomes of this approach did not have sense. After that, the manager of this organization recommended model key process. The AGILIPO methodology does not provide any information about it and based on this experience, we learned that we should model key process with this methodology.

The experience in applying AGILIPO provided evidence of the conditions necessary to use AGILIPO. One is the training of the basic concepts of BPM and BPM of the AGILIPO team [2]. During the first stage of the experience the investigators interviewed project managers and realized that they had few knowledge about BPM and agile BPM. The investigators suggest to the AGILIPO team to have a training session for all interviewers and the AGILIPO team.

The experience to apply AGILIPO gave evidence on the conditions in order to use AGILIPO. One is to define the roles and the levels of the organization chart that they should be represented in the equipment AGILIPO [2]. Based on experience the investigators suggested including all levels of the organization chart and key persons with a deep knowledge of the unit and organization.

In addition, the experience in applying AGILIPO, there is evidence of some limitations in the application of AGILIPO, which are the classification of the processes. Thus, the investigators suggest change to the classification of processes of the Massachusetts Institute of Technology (MIT) or the framework of classification of the processes of the American Productivity and Quality Center. (APQC) [2].

The experience to apply AGILIPO gave evidence on the issues of working with podcasts to implement AGILIPO. The AGILIPO team agreed that was hard to follow a description of a process listening podcasts. Besides, tune the description by folksonomy. In the case of using blogs to describe and fine-tuning the description of the process through folksonomy the AGILIPO team agreed that was more complicated to follow the comments, feed backs and get a consensus. They spend more time reading the blogs to label the key process of PAHO/WHO Nicaragua.

The experience in applying AGILIPO, there is evidence of some limitations of podcasts and blog and the Wiki is feasible for AGILIPO.

In this paper it was verified that the use of social network tools is useful in the management of business processes. Since these can facilitate the interaction within the organization [24].
In addition, the experience in applying AGILIPO and responding a request of the AGLIPO team for improve the process obtained in the second stage of the experience. The improved process of services contracts combined effectively the process of recruitment temporary staff and services contracts. The result diagram was very easy to understand and few tasks.

After analyzing the description of the improved process of service contracts using blogs approach and applying the best practices of Bizagi, the investigators create a new BPM diagram of the improved process of service contract. The AGILIPO team agreed that some steps of both process could be combined and improve the logic sequence of the process. The result diagram was easy to understand for the team. In $2016 \mathrm{PAHO} / \mathrm{WHO}$ started the second phase of the implementation of the new Enterprise Resources Planning (ERP) and that ERP reduced most of the process.

The authors hope that other research of the proposal of the AGILIPO methodology is developed in other organizations using the Wiki.

\section{Conflict of Interest}

The authors declare no conflict of interest.

\section{Acknowledgment}

The authors thank Dr. Socorro Gross, Representative of PAHO/WHO Nicaragua to permit use information on the Representative Office to conduct this research.

\section{References}

[1] M. Hammer, Reengineering Work: Don't automate, obliterate, Harvard Business Review, vol. 68, 1990.

[2] D. Rodríguez, "Gestión por Procesos de Negocio (BPM) - Una experiencia de aplicación de AGILIPO en una organización en Nicaragua”, 2017.

[3] T. Koulopoulos, "Taming the Unpredictable". Future Strategies Inc. 1st Edition.

[4] D. Rodriguez, E. Silva, The experience of implementation with Agile Business Process, Management, CONCAPAN XXX -VII-IEEE, 2017.

[5] B. Hitpass, "BPM: Business Process Management - Fundamentos y Conceptos de Implementación”. BHH Ltda. Cuarta edición. 2017.

[6] T. Benedict, N. Bilodeau, P. Vitkus, E. Powell, D. Morris, M. Scarsig, D. Lee G. Field, T. Lohr, R. Saxena et al., "BPM CBOK Version 3.0: Guide to the Business Process Management Common Body Of Knowledge version 3.0", 3nd Edition, CreateSpace Independent Publishing Platform,2013.

[7] J. Sinur, J. Odell, P. Fingar. Business Process Management: The Next Wave, 2013.

[8] Germany Trade and Invest (GTAI), Promoted by Federal Ministry for Economic Affairs and Energy in Accordance with a German Parlament Resolution. Berlin, 2016.

[9] B. Hitpass, H. Astudilo, Industry 4.0 Challenges for Business Process Management and Electronic-Commerce, Journal of Theoretical and Applied Electronic Commerce Research, Universidad de Talca, Chile, 2019.

[10] M. La Rosa, "Strategic Business Process Management", Queensland University of Technology, 2016.

[11] R. Thomsett, “Agile Business: The Final Frontier", www.cutter.com. 2010.

[12] M. Zacarias, P. Ventura, "Agile Business Process and Practice Alignment Methodology: A Case-Study-Based Analysis".IGI Global, 2018..

[13] P. Bernus, J. Blazewiez, G. Schmidt, M. Shaw, "International Handbooks on Information Systems", 2010.

[14] S. Simmons, Steele, M., "BPM Voices: Synchronicity: An agile approach to business process management". 2012.

[15] R. Meziani, R. Magalhaes, "Proposal for an Agile Business Process Management Methodology". First International Workshop on Organizational Design and Engineering. 2009.

[16] M. Kamel, I. Maramba, S. Wheeler, "Wikis, blogs, and podcasts: a new generation of Web-based tools virtual collaborative clinical practice and education", BMC Medical Education, 2006. 
[17] T. Morgan, Business Rules and Information Systems: Aligning IT with Business Goals, Addison Wesley, 2002.

[18] M. Cumberlidge, "Business Process Management with JBoss, jBPM", Packt Publishing -Birmingham, 2012.

[19] S. Allibang, "BPM: Business Process Management (BPM) of Small and Medium Enterprises", DBest Reads, 2016.

[20] A. Kumar, Business Process Management, Taylor and Francis, 2018.

[21] F. Dengler, D. Vrandecic, "Wiki-Based Maturing Of Process Descriptions". International Conference on Business Process Management. 2011.

[22] O. Hatzi, G. Meletakis, M. Nikolaidou, D. Anagnostopoulos, "Collaborative management of applications in enterprise social networks". International Research Challenges in Information Science, 2014.

[23] Bizagi Process Modeler User Guide, 2016.

[24] M. Rosing, A. Scheer, H. Scheel, "The Complete Business Process Handbook: Body of Knowledge from Process Modeling to BPM", Volume I, Morgan Kaufmann Publisher, 2015.

[25] M. Zacarias, P. Ventura, "Agile Business Process and Practice Alignment Methodology: A Case-Study-Based Analysis".IGI Global, 2018. 